\title{
Voltage Quality and Power Factor Improvement in Smart Grids Using Controlled DG Units
}

\author{
Ibrahim Ahmad ${ }^{1, *}$, Ghaeth Fandi ${ }^{1,2} \mathbb{C}$, Zdenek Muller ${ }^{1}$ and Josef Tlusty ${ }^{1,3}$ \\ 1 Department of Electrical Power Engineering, Faculty of Electrical Engineering, Czech Technical University in \\ Prague, Technická 2, 16627 Prague 6, Czech Republic \\ 2 Department of Sustainable Technologies, Faculty of Tropical AgriSciences, Czech University of Life Sciences \\ Prague, Kamýcká 961/129, 16500 Prague 6, Czech Republic \\ 3 Department of Health Care Disciplines and Population Protection, Faculty of Biomedical Engineering, \\ Czech Technical University in Prague, Sportovců 2311, 27201 Kladno, Czech Republic \\ * Correspondence: ahmadibr@fel.cvut.cz; Tel.: +42-022-435-3943
}

Received: 20 July 2019; Accepted: 2 September 2019; Published: 6 September 2019

check for updates

\begin{abstract}
The increased penetration of renewable energy sources in the electrical grid, due to the rapid increase of power demand and the need of diverse energy sources, has made distributed generation (DG) units an essential part of the modern electrical grid. The integration of many DG units in smart grids requires control and coordination between them, and the grid to maximize the benefits of the DG units. Smart grids and modern electronic devices require high standards of power quality, especially voltage quality. In this paper, a new methodology is presented to improve the voltage quality and power factor in smart grids. This method depends on using voltage variation and admittance values as inputs of a controller that controls the reactive power generation in all DG units. The results show that the controller is efficient in improving the voltage quality and power factor. Real data from an electrical network have been used in the simulation model in MATLAB Simulink to test the new approach.
\end{abstract}

Keywords: voltage quality; power factor; smart grids; distributed generation; renewable energy; power quality

\section{Introduction}

Renewable energy sources (RES) especially wind, solar and biomass have become an important part of modern grids, and it is predicted that the number of RES units will increase rapidly within the European Union where, according to [1], the share of renewable energy sources (RES) will rise substantially, achieving at least 55\% of gross final energy consumption in 2050 . Further, renewables will account for almost one-third of the total electricity output in the world by 2035 [2]. Thus, a new term was created: distributed generation (DG) or decentralized generation. DG can be defined as on-site generation which is directly connected to the distribution networks in order to support the grid on distribution levels [3]. There are a lot of benefits of DG, such as reducing transmission and distribution costs and increasing the efficiency of energy [4]. Also, DG units play an important role in minimizing pollution, especially $\mathrm{CO}_{2}$ [5]. Moreover, DG could play a big role in security and emergency energy systems for cities, as mentioned in [6] for Latakia city. In addition, photovoltaic energy systems in homes increases the efficiency of networks both in capital and utilization rates [7]. DG units could also be used to maximize the voltage profile and minimize power loss [8]. These units vary between non-traditional units such as wind turbines, photovoltaic farms, and fuel cells, as well as traditional generators such as micro turbines, therefore, modern grids have become more complex [9]. 
The increased numbers of DG units in the grids require operators and designers to deal with a greater number of power sources and more complex systems.

The increased complexity of electrical grids and high sensitivity of modern devices demand high quality, reliability, and flexibility in the modern electrical networks. The rapid development of technology and control systems has driven electricity companies and operators to transition from conventional grids to smart grids. The term 'smart grid' according to the (EU) vision, refers to the intelligent integration of all generations and consumers in order to provide a reliable, secure, economic, and sustainable energy supply [10]. In fact, many technical and business challenges have been raised with respect to the integration of the DG units in smart grids [11].

Power quality is one of the essential needs of obtaining a reliable energy supply in smart grids, where the appropriate power quality maintains the extent of compatibility between all the equipment of grid parts [12]. The importance of power quality is based on serious problems that could occur when power quality is lacking - such difficulties could include, but are not limited to, troubles related to essential business applications, sensitive industrial processes, and important public services, i.e., hospitals and traffic control [13]. Power quality issues could be classified into five categories: short duration variation, long duration variation (and power factor), transients, voltage imbalance, and waveform distortion [14]. Long duration variations have long term impacts on voltage quality, so it is important to minimize them as much as possible. Lots of research has been done regarding the improvement of voltage quality. Various algorithms and techniques have been used in this field of research. The techniques used have been applied to different parts of the electrical grid. Some research has used the optimal sizing and location of DG units to improve the voltage profile [15] in which a practical swarm optimization has been applied, while the immune algorithm has been used in [16]. The authors of [17] proposed a control method for small domestic power plants using renewable energy to reduce total harmonic distortion, and [18] used a three-phase inverter together with a new control algorithm connected to a renewable source in order to reduce voltage unbalance. Further, the imperialist competitive algorithm has been used in [19], as well as voltage indexing and the heuristic method in [20], while [21] used an experimental method to define the optimal location. Other methods have been relied upon as control techniques to drive the DG units themselves. In [22], a hierarchical control has been proposed, consisting of a primary and a secondary level, in order to compensate sensitive load bus voltage unbalance in addition to harmonics. Meanwhile, [23] proposed another method which relies upon the central control of power share and voltage profile improvement, at the same time as the orders are sent through a communication link with a low band-width. Local control is used as well in [24] which allows the operator of the distribution system and power producers to obtain benefits by providing the operator with an ancillary voltage regulation service.

As there is a strong relationship between voltage and reactive power, voltage var control is one of the most affected techniques in improving the voltage profile for the whole electrical system [25]. Various techniques have been used to improve the voltage quality and profile using voltage var control. The authors of [26] used an adaptive voltage var control algorithm to balance the need for power quality (voltage regulation) and minimize power loss. Reactive power is controlled through the inverter on the photovoltaic cells. In [27], the authors deal with optimization issues for the local reactive power control of voltage profiles in medium voltage (MV) radial distribution systems using wind farms, whereby an optimal sensitivity approach using a voltage control reference has been applied to the proposed distribution network. The authors of [28] applied their method using photovoltaic generation as a DG unit, in which the calculation rule of the control reference has been developed using optimal data, which consist of relations between randomly given inputs and corresponding optimal outputs as calculated by an optimization technique. In [29], an optimized distributed control technique has been proposed relying on the sensitivity analysis of the distribution network and decentralized power regulation to improve voltage quality, and it was applied on a radial network. Meanwhile, another approach, which uses average changes of sending and receiving voltage in addition to voltage drop, has been proposed in [30] and it has been applied to a radial network. 
All previous research did not take into account the location of the DG which has a valuable impact on the efficiency of the control algorithm in improving the voltage quality. In contrast, the previous research was applied on radial systems, which consist of one power source and many transmissions lines and loads, but real electrical systems have more complex architecture. Mesh grids consist of many power sources, transmission lines, and loads. This type of grid also has some radial parts. In this research, we used both of the voltage deviation values for all grid busbars and the influence of the DG unit location (i.e., admittance matrix). Furthermore, we applied the proposed approach to a mesh grid instead of a radial one.

This paper presents the extension and completion of previous works in the field of voltage var control. Moreover, the new approach involves a new important parameter in the proposed controller which is the admittance value between the DG unit and the busbars in addition to the voltage variations. These two parameters have a significant impact on the reactive power flow and voltage profile. The used data in the simulation model are from a real network. We made different scenarios of loads to test the performance of the model in various cases. In this work, we focus on improving voltage quality by minimizing the long duration variations of voltage and improving power factor to achieve better voltage quality. The model is created using MATLAB Simulink software.

The new technique depends on the admittance's values between DG units and busbars, in addition to the voltage deviation values of busbars as an input of the controller which will control the reactive power generation from all DG units in order to improve the voltage quality and power factor in the grid. In fact, controlling voltage in far busbars is a very hard mission if we do not have close control tools to these busbars. As DG units become an essential part of the smart grid, we can use them as a voltage control tool. DG units could be equipped with full scale converter, so they are capable to generate reactive power separately from active power [31]. Moreover, there is a strong relation between the voltage profile and reactive power. Technically, we will get better a voltage profile when the reactive power is generated closer to the busbars. The admittance values between DG units and busbars give us a very good parameter for how far the DG unit is from the busbars, so we will be able to identify the suitable reactive power which must be generated.

\section{Methodology}

In our methodology, we assume that we have a general electrical system, as shown in Figure 1, which consists of many generators, G1, G2, G3, etc. which feed many loads through transmission lines between busbars. These loads are connected to $n$ busbars. In this electrical system, there are also many DG units equipped with converters.

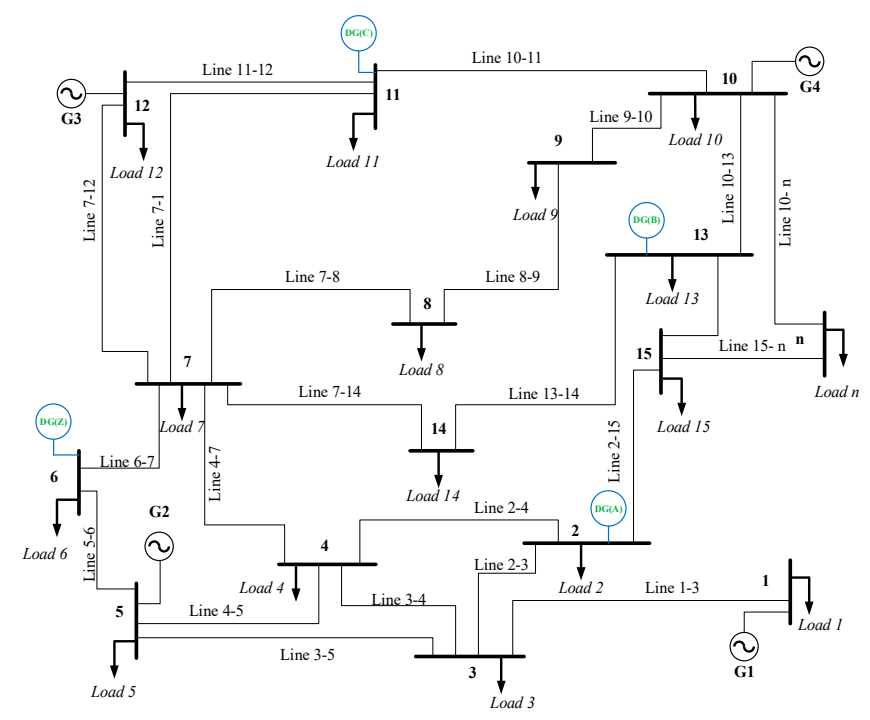

Figure 1. General electrical system. 
The DG units used in this research are wind farms type 4 [32], which consist of a permanent magnet synchronous generator PMSG and have a full-scale converter. These wind farms are capable of generating both active and reactive power separately. The structure of the control system is illustrated in Figure 2. The input signals of the controller are the measured values of voltage and admittance, and the output control signal is $Q_{\text {ref }}$.

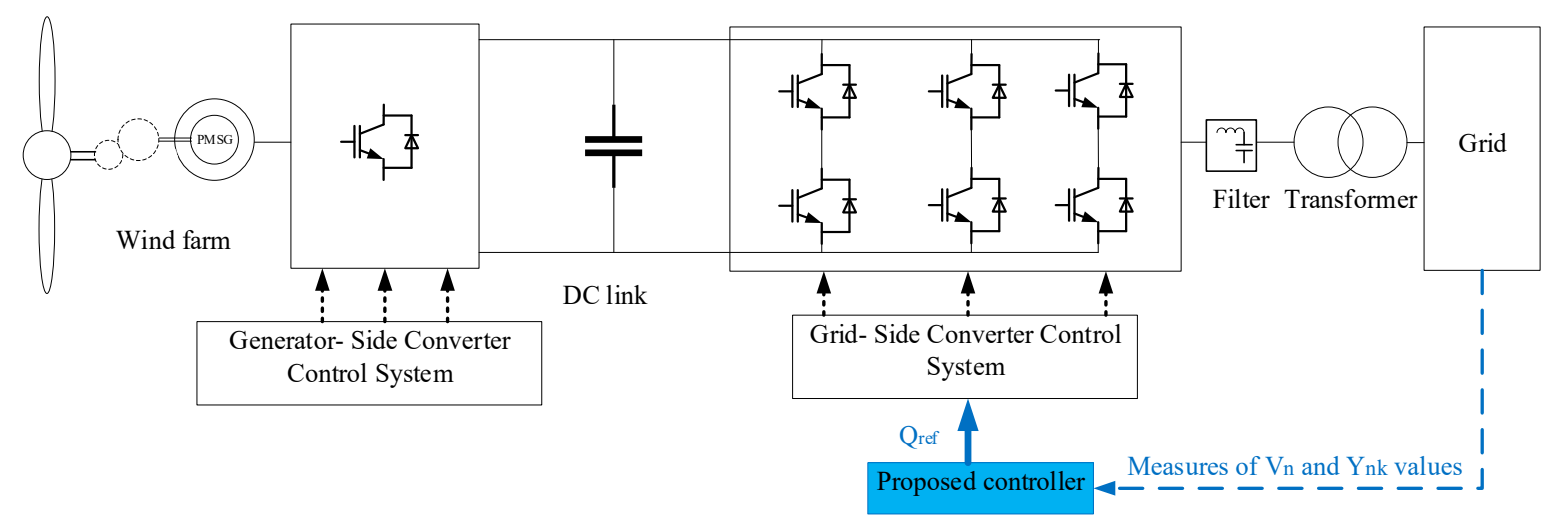

Figure 2. Control system structure.

Due to the impedance of transmission lines and load changes, we will not obtain nominal voltage at the busbars and there will be voltage deviations. Therefore, we will assume that voltage values at busbars are $V_{1}, V_{2}, V_{3}, \ldots . V_{n}$, voltage deviations are $d V_{1}, d V_{2}, d V_{3}, \ldots . d V_{n}$ and voltage deviations percentages are $d V_{1} \%, d V_{2} \%, d V_{3} \%, \ldots . d V_{n} \%$. The voltage deviation percentage is defined as in the following Equation:

$$
d V_{n} \%=\frac{V_{S}-V_{n}}{V_{S}} \times 100
$$

where $V_{S}$ represents the nominal voltage and $V_{n}$ represents the measured voltage of busbar $n$.

First, we will measure the impedance values $Z$ and, by inverting them (as $Y=\frac{1}{Z}$ ), we can get admittance values between each busbar and the DG units, where for the first busbar the admittance between it and DG units will be $Y_{1 A}, Y_{1 B}, Y_{1 C}, \ldots . Y_{1 Z}$. These values represent the admittance between busbar 1 and DG unit $A, B, C, \ldots, Z$ respectively, as well as the same for other busbars. So, we will obtain the end result of all admittance values according to the following Equation:

$$
y=\left[\begin{array}{cccc}
Y_{1 A} & Y_{1 B} & \ldots & Y_{1 Z} \\
Y_{2 A} & Y_{2 B} & \ldots & Y_{2 Z} \\
\ldots & \ldots & \ldots & \ldots \\
Y_{n A} & Y_{n B} & \ldots & Y_{n Z}
\end{array}\right]
$$

Now, we will identify a new factor which we will call admittance factor $y^{\prime}$. The admittance factor for the first DG unit is:

$$
y_{1 A}^{\prime}=\frac{Y_{1 A}}{Y_{1 A}+Y_{1 B}+Y_{1 C}+\ldots+Y_{1 Z}}=\frac{Y_{1 A}}{\sum_{k=A}^{Z} Y_{1 k}}
$$

where k represents DG unit (A, B, C, . , Z).

As well as the same for other busbars and DG units. 
Obviously, the admittance factor will be bigger for the closer DG unit and vice versa. So, we will get the admittance factors matrix as shown in the following Equations:

$$
\begin{gathered}
y^{\prime}=\left[\begin{array}{cccc}
\frac{Y_{1 A}}{\sum_{k=A}^{Z} Y_{1 k}} & \frac{Y_{1 B}}{\sum_{k=A}^{Z} Y_{1 k}} & \cdots & \frac{Y_{1 Z}}{\sum_{k=A}^{Z} Y_{1 k}} \\
\frac{Y_{2 A}}{\sum_{k=A}^{Z} Y_{2 k}} & \frac{Y_{2 B}}{\sum_{k=A}^{Z} Y_{2 k}} & \cdots & \frac{Y_{2 Z}}{\sum_{k=A}^{Z} Y_{2 k}} \\
\ldots & \ldots & \cdots & \ldots \\
\frac{Y_{n A}}{\sum_{k=A}^{Z} Y_{n k}} & \frac{Y_{n B}}{\sum_{k=A}^{Z} Y_{n k}} & \cdots & \frac{Y_{n Z}}{\sum_{k=A}^{Z} Y_{n k}}
\end{array}\right] \\
y^{\prime}=\left[\begin{array}{clll}
y_{1 A}^{\prime} & y_{1 B}^{\prime} & \cdots & y_{1 Z}^{\prime} \\
y_{2 A}^{\prime} & y_{2 B}^{\prime} & \cdots & y_{2 Z}^{\prime} \\
\ldots & \ldots & \cdots & \ldots \\
y_{n A}^{\prime} & y_{n B}^{\prime} & \cdots & y_{n Z}^{\prime}
\end{array}\right]
\end{gathered}
$$

DG units are equipped with converters so, they are capable of changing the angle between voltage and current consequently the generated reactive power. In smart grids, obtaining a steady and stable voltage with small voltage variation from the nominal voltage is very important, especially for highly sensitive electronic devices. In our methodology, DG units have been controlled to produce reactive power according to the voltage deviations of busbars and the varying admittance factors between busbars and DG units. To compensate for any increase in voltage deviation, we need to increase the generated reactive power. In the same vein, the generated reactive power must come from the closest DG unit which will have the highest value of the impedance factor. For the first busbar, the voltage deviation percentage is $d V_{1} \%$-thus, the generated reactive power as a percentage value is given according to the following Equation:

$$
Q_{1 A} \%=\frac{d V_{1}}{d V_{\text {Allowed }}} \cdot y_{1 A}^{\prime}
$$

where $d V_{\text {Allowed }}$ is the maximum allowed voltage deviation in the electrical grid.

The same was done for other busbars and DG units. Therefore, we obtain the matrix of reactive power percentages for all DG units as shown in the following Equations:

$$
\begin{gathered}
Q \%=\left[\begin{array}{cccc}
\frac{d V_{1}}{d V_{\text {Allowed }}} \cdot y_{1 A}^{\prime} & \frac{d V_{1}}{d V_{\text {Allowed }}} \cdot y_{1 B}^{\prime} & \cdots & \frac{d V_{1}}{d V_{\text {Allowed }}} \cdot y_{1 Z}^{\prime} \\
\frac{d V_{2}}{d V_{\text {Allowed }}} \cdot y_{2 A}^{\prime} & \frac{d V_{2}}{d V_{\text {Allowed }}} \cdot y_{2 B}^{\prime} & \cdots & \frac{d V_{2}}{d V_{\text {Allowed }}} \cdot y_{2 Z}^{\prime} \\
\ldots & \ldots & \cdots & \cdots \\
\frac{d V_{n}}{d V_{\text {Allowed }}} \cdot y_{n A}^{\prime} & \frac{d V_{n}}{d V_{\text {Allowed }}} \cdot y_{n B}^{\prime} & \cdots & \frac{d V_{n}}{d V_{\text {Allowed }}} \cdot y_{n Z}^{\prime}
\end{array}\right] \\
Q \%=\left[\begin{array}{cccc}
Q_{1 A} \% & Q_{1 B} \% & \ldots & Q_{1 Z} \% \\
Q_{2 A} \% & Q_{2 B} \% & \ldots & Q_{2 Z} \% \\
\ldots & \ldots & \ldots & \cdots \\
Q_{n A} \% & Q_{n B} \% & \ldots & Q_{n Z} \%
\end{array}\right]
\end{gathered}
$$

Next, we can find the total reactive power which must be generated by DG units. For the DG unit (A) we find:

$$
Q_{A} \%=Q_{1 A} \%+Q_{2 A} \%+\ldots+Q_{n A} \%=\sum_{i=1}^{n} Q_{i A} \%
$$

where $i$ represents busbar number. 
The same applies to other DG units. Therefore, the total needed reactive power for all DG units are obtained by the following Equation:

$$
Q_{T} \%=\left[\begin{array}{c}
Q_{A} \% \\
Q_{B} \% \\
\cdots \\
Q_{Z} \%
\end{array}\right]=\left[\begin{array}{c}
\sum_{i=1}^{n} Q_{i A} \% \\
\sum_{i=1}^{n} Q_{i B} \% \\
\ldots \\
\sum_{i=1}^{n} Q_{i Z} \%
\end{array}\right]
$$

The generated reactive power as a real value [Var] will be:

$$
Q_{A}=Q_{A} \% \cdot Q_{T A}
$$

where $Q_{T A}$ is the maximum reactive power of the DG unit $(A)$.

The same applies as well for other DG units. Therefore, the total required reactive power for all DG units is:

$$
Q_{T}=\left[\begin{array}{c}
Q_{A} \\
Q_{B} \\
\cdots \\
Q_{Z}
\end{array}\right]=\left[\begin{array}{c}
Q_{A} \% \cdot Q_{T A} \\
Q_{B} \% \cdot Q_{T B} \\
\cdots \\
Q_{Z} \% \cdot Q_{T Z}
\end{array}\right]
$$

The proposed control algorithm of busbar 1 is shown in Figure 3:

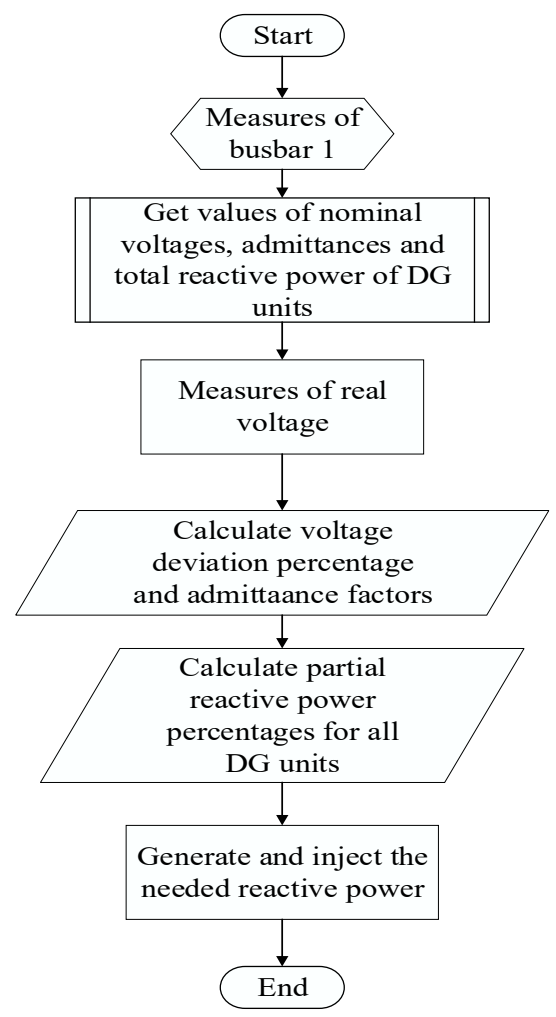

Figure 3. Proposed control algorithm of busbar No. 1.

The proposed control algorithm for the entire system is shown in Figure 4: 


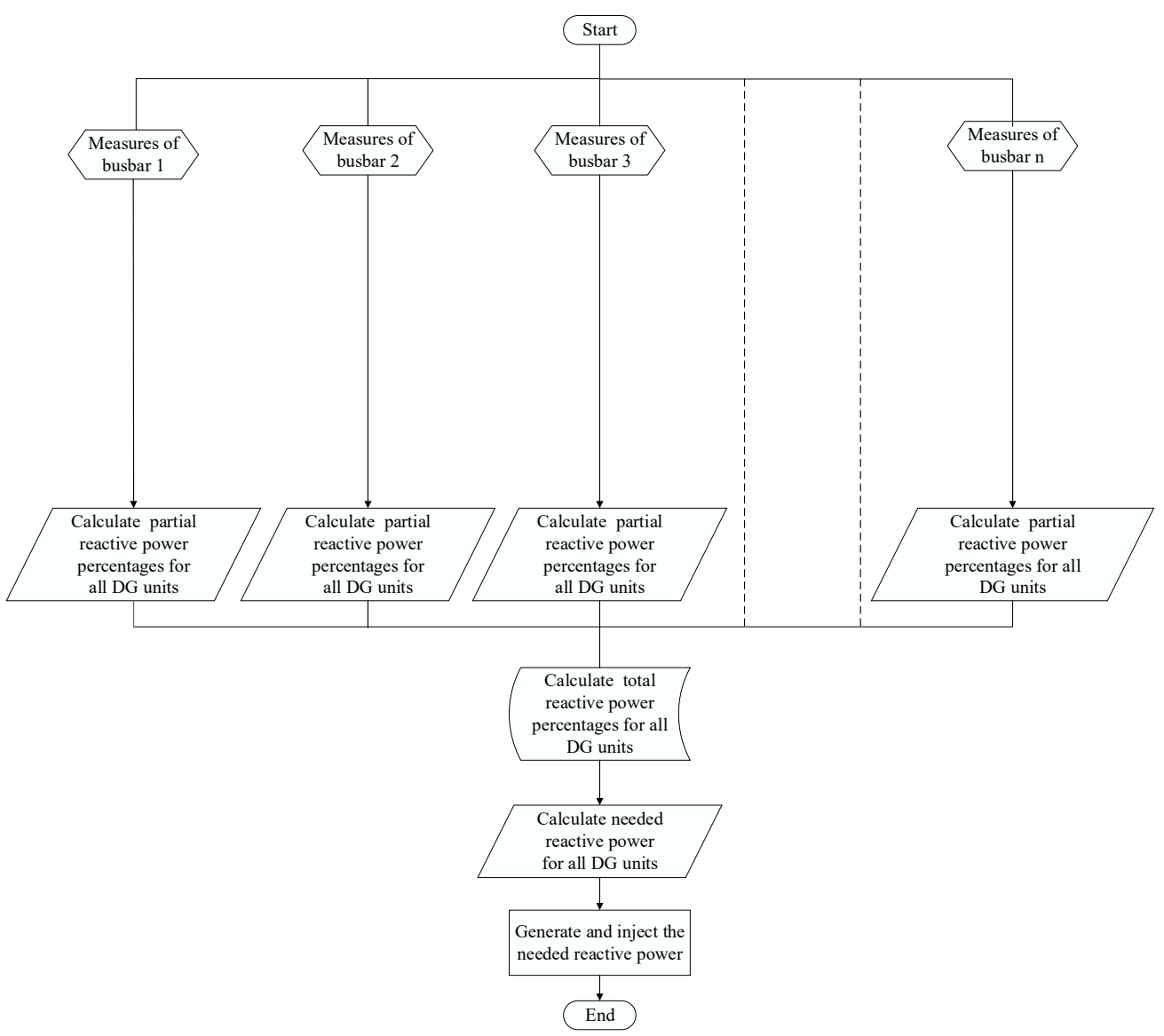

Figure 4. Proposed algorithm for the entire system.

\section{Case Study}

\subsection{Mesh Grid}

The methodology has been applied to the real electrical system which is shown in Figure 5. The electrical system consists of the following:

1. Two power sources (G1 and G2) which supply electrical energy to the system through two power transformers 230/66 kV.

2. Eight transmission lines which form the mesh grid. The length of lines are $\left(L_{0-2}=50 \mathrm{~km}\right.$, $L_{2-3}=20 \mathrm{~km}, L_{3-5}=25 \mathrm{~km}, L_{0-1}=30 \mathrm{~km}, L_{1-2}=60 \mathrm{~km}, L_{3-4}=50 \mathrm{~km}, L_{1-4}=35 \mathrm{~km}, L_{4-6}=$ $30 \mathrm{~km})$.

3. Six power transformers $66 / 20 \mathrm{kV}$ which supply power to six loads.

4. Six loads with different values $\left(S_{1}=20+j 6 \mathrm{MVA}, S_{2}=22+j 7 \mathrm{MVA}, S_{3}=18+j 4 \mathrm{MVA}\right.$, $\left.S_{4}=14+j 4 \mathrm{MVA}, S_{5}=12+j 3 \mathrm{MVA}, S_{6}=12+j 4 \mathrm{MVA}\right)$.

5. Three DG units which are connected to three different locations (Busbar 1, Busbar 2, and Busbar 4) with different capacities $\left(S_{A}=15.56 \mathrm{MVA}, S_{B}=26.67 \mathrm{MVA}, S_{C}=35.56 \mathrm{MVA}\right.$.). These DG units are equipped with a full scale converter. These DG units are connected to the grid using three transformers which have the parameters as in Tables A1-A3.

\subsection{Simulation and Procedures}

First, we built the Simulink model of the electrical grid then the Simulink model of the controller that accords to our methodology containing six busbars and three DG units. In order to construct the controller, we needed to measure admittance values and admittance factors because they are constant inputs of the controller. Measuring these values could be done by measuring the impedance between 
the DG units and busbars and then inverting the impedance value as $Y=\frac{1}{Z}$ and we got these values from the real grid. Admittance values include transmission lines and transformers. After measuring the admittance values, we can calculate admittance factors using Equation (3). The following constant values have been obtained:

$$
y^{\prime}=\left[\begin{array}{lll}
y_{1 A}^{\prime} & y_{1 B}^{\prime} & y_{1 C}^{\prime} \\
y_{2 A}^{\prime} & y_{2 B}^{\prime} & y_{2 C}^{\prime} \\
y_{3 A}^{\prime} & y_{3 B}^{\prime} & y_{3 C}^{\prime} \\
y_{4 A}^{\prime} & y_{4 B}^{\prime} & y_{4 C}^{\prime} \\
y_{5 A}^{\prime} & y_{5 B}^{\prime} & y_{5 C}^{\prime} \\
y_{6 A}^{\prime} & y_{6 B}^{\prime} & y_{6 C}^{\prime}
\end{array}\right]=\left[\begin{array}{lll}
0.9748 & 0.0135 & 0.0131 \\
0.0061 & 0.9900 & 0.0045 \\
0.2566 & 0.4826 & 0.2622 \\
0.0038 & 0.0029 & 0.9936 \\
0.2967 & 0.4030 & 0.3003 \\
0.2688 & 0.2340 & 0.4972
\end{array}\right]
$$

After building the whole Simulink model, we then divided the results into two groups. The first group was the (Normal) group which operated the model without DG units. The second was the (Controlled DG) group which operated the model after integrating the DG units that were equipped with our controller. Each group was examined under different values of loads using four ascending values of loads as shown in Table 1.

Table 1. Loads values for all steps.

\begin{tabular}{ccccc}
\hline Load No. & Step 1 (MVA) & Step 2 (MVA) & Step 3 (MVA) & Step 4 (MVA) \\
\hline Load 1 & $20+j 6$ & $22+j 7$ & $24+j 8$ & $26+j 9$ \\
Load 2 & $22+j 7$ & $24+j 8$ & $26+j 9$ & $28+j 10$ \\
Load 3 & $18+j 4$ & $20+j 5$ & $22+j 6$ & $24+j 7$ \\
Load 4 & $14+j 4$ & $16+j 5$ & $18+j 6$ & $20+j 7$ \\
Load 5 & $12+j 3$ & $14+j 4$ & $16+j 5$ & $18+j 6$ \\
Load 6 & $12+j 4$ & $14+j 5$ & $16+j 6$ & $18+j 7$ \\
\hline
\end{tabular}

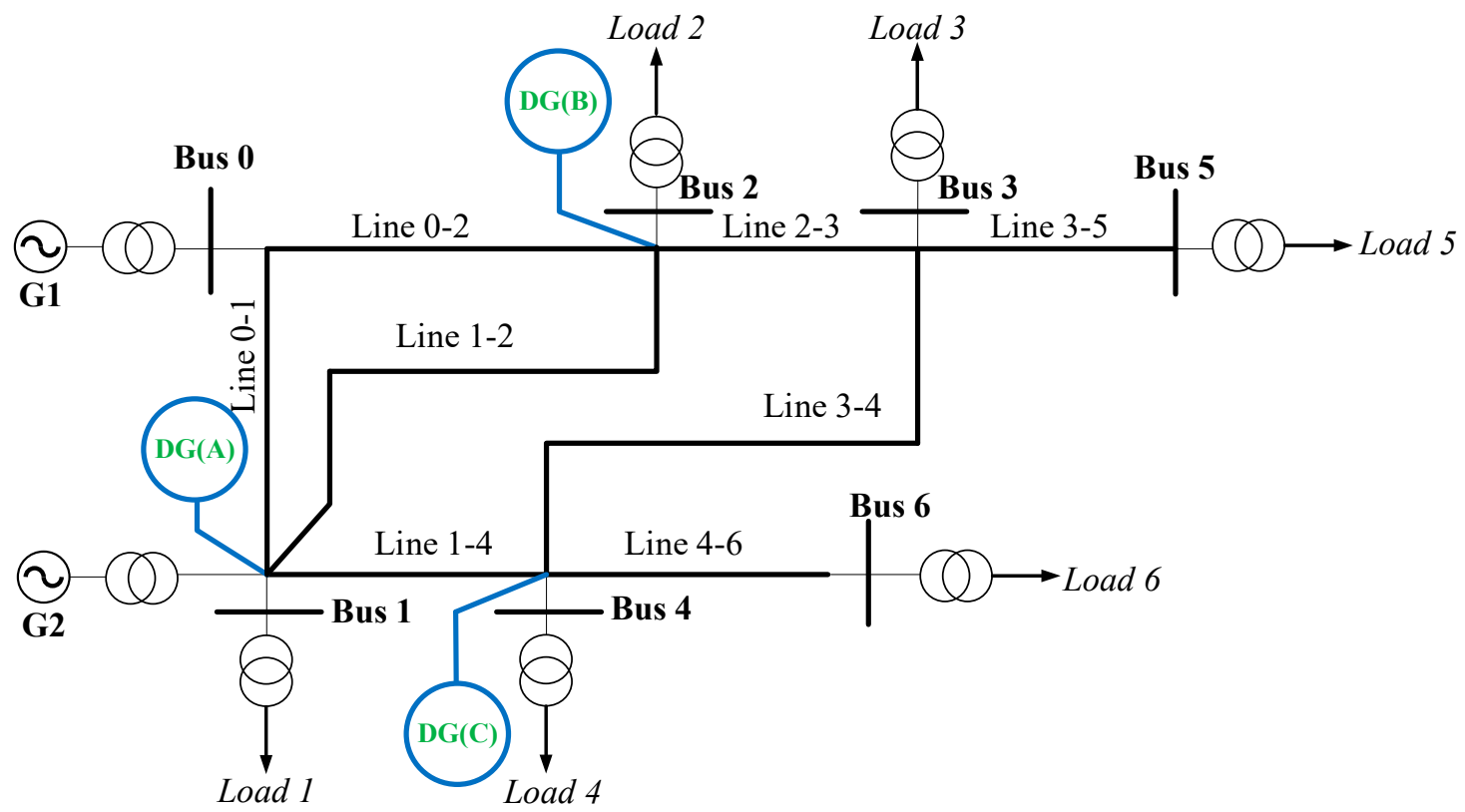

Figure 5. Proposed mesh grid.

This controller used voltage deviation and admittance values as input values in order to improve the voltage quality in the network. The obtained results from both groups were compared to specify the proposed controller's capability of improving the voltage quality and power factor of the electrical grid. 


\section{Results}

\subsection{Voltage Deviation \% of Busbars}

Figure 6 shows the percentage of voltage deviation for each busbar, 1,2,3,4,5, and 6, in two cases (Normal) and (Controlled DG), and for four steps of load values. We concluded the following:

1. For busbar No.1: Voltage deviation percentage in the (Normal) case ranges between $1.7 \%$ and $2.7 \%$ whereas, in the (Controlled DG) case, the range is between $0.3 \%$ and $0.5 \%$. Moreover, we observed that the controller was able to maintain the voltage values to within a very narrow range of change (only $0.2 \%$ ) during the ascent of load values, whereas the range in the (Normal) case is $1 \%$.

2. For busbars No. 2,3,4,5, and 6: The voltage deviation percentage attitude is similar to that for bus No.1, but with different values and ranges whereby all values of the voltage deviation percentage, and change ranges of it, are noticeably smaller and narrower for the (Controlled DG) case compared to (Normal) case.

3. We also noticed that the highest voltage deviation percentages are for bus bar No. 5 and 6 because these busbars are radial and connected to radial branches of the mesh grid, so they obtain power through one transmission line. For these busbars, the voltage deviation percentage reaches over $10 \%$ in the (Normal) case, which is the maximum allowed limit of voltage deviation percentage.

4. Although there is a high voltage deviation percentage for busbars No. 5 and 6 , the controller was able to decrease it remarkably, up to $5.5 \%$ for busbar No. 5 and 3.5\% for busbar No. 6, even for the highest load value.

5. The percentage values of voltage deviation are smaller, the change ranges are narrower, and the controller is more efficient for busbars 1,2 and 6. This is due to the fact that they are closer to the DG units and the power sources G1 and G2.

Figure $6 \mathrm{~g}$ and Table A4 illustrate the voltage deviation percentages for all buses in the two cases (Normal) and (Controlled DG). For four steps of load values, we can notice the significant impact of the controller in decreasing the voltage deviation percentages and thus improving voltage quality and profile.

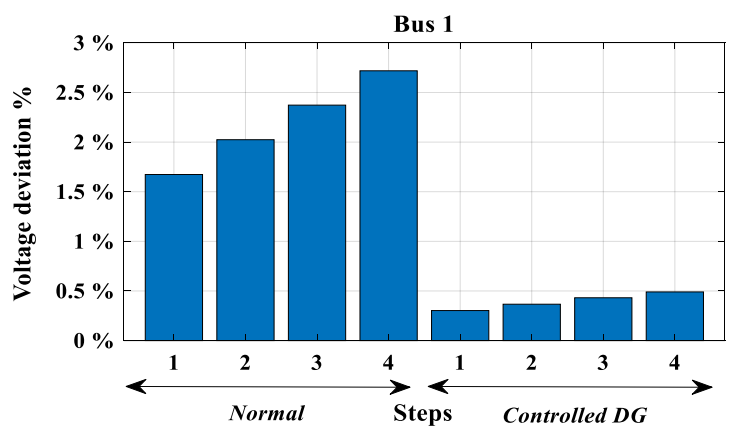

(a)

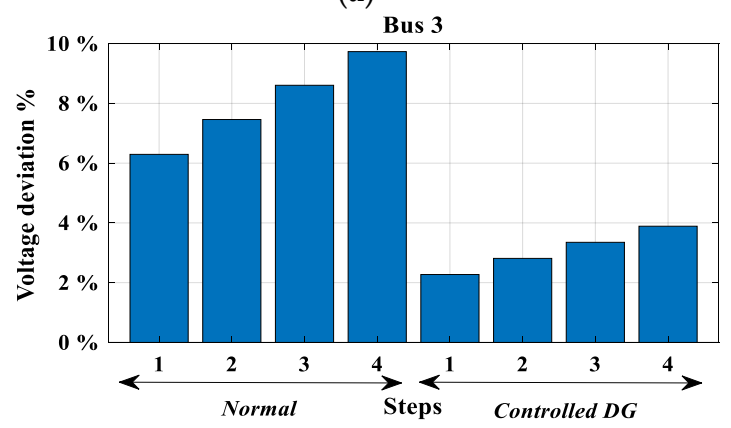

(c)

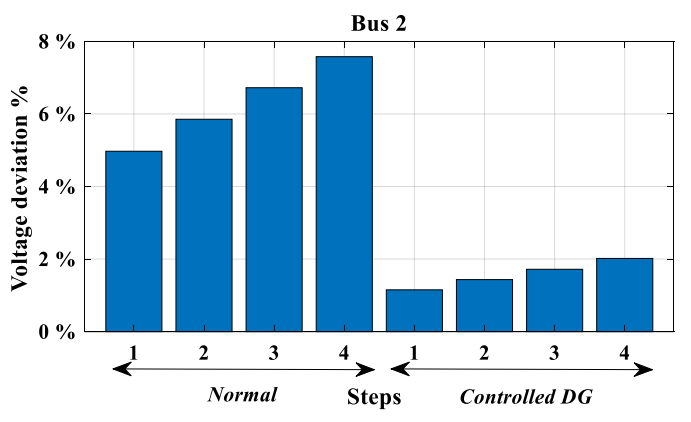

(b)

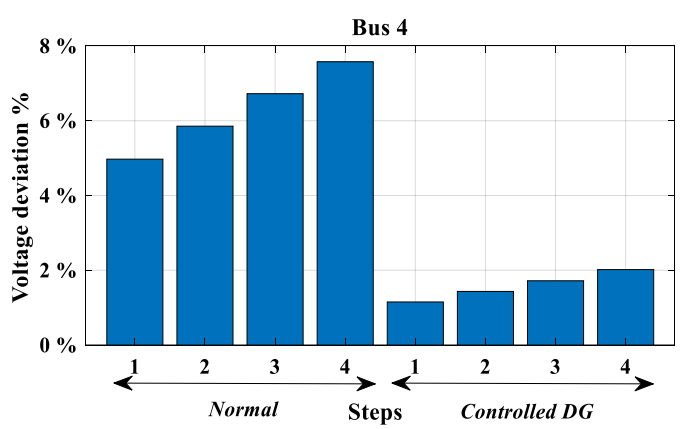

(d)

Figure 6. Cont. 


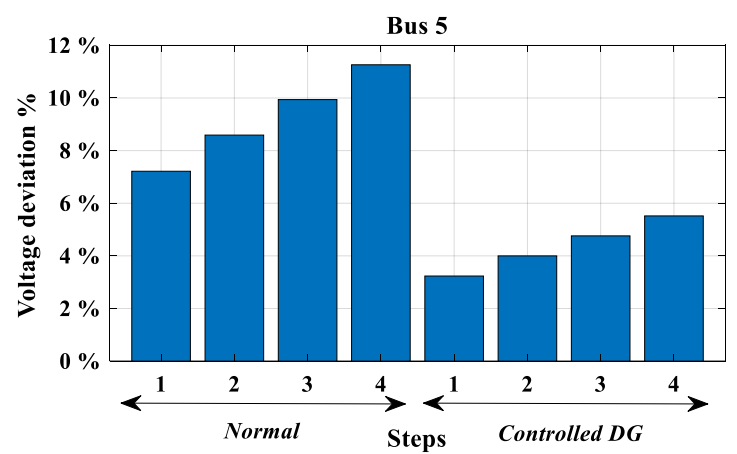

(e)

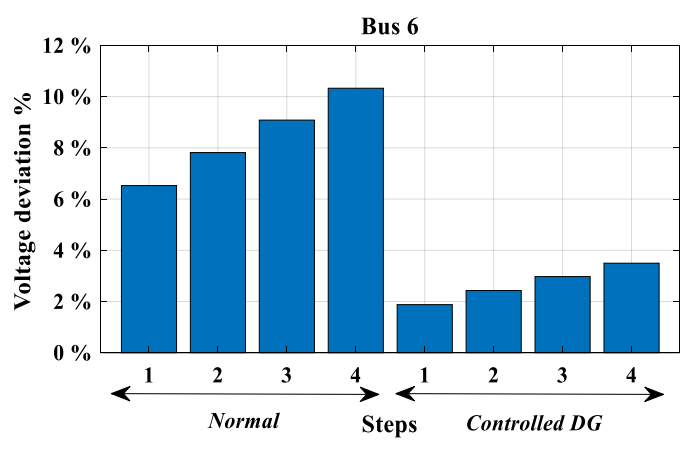

(f)

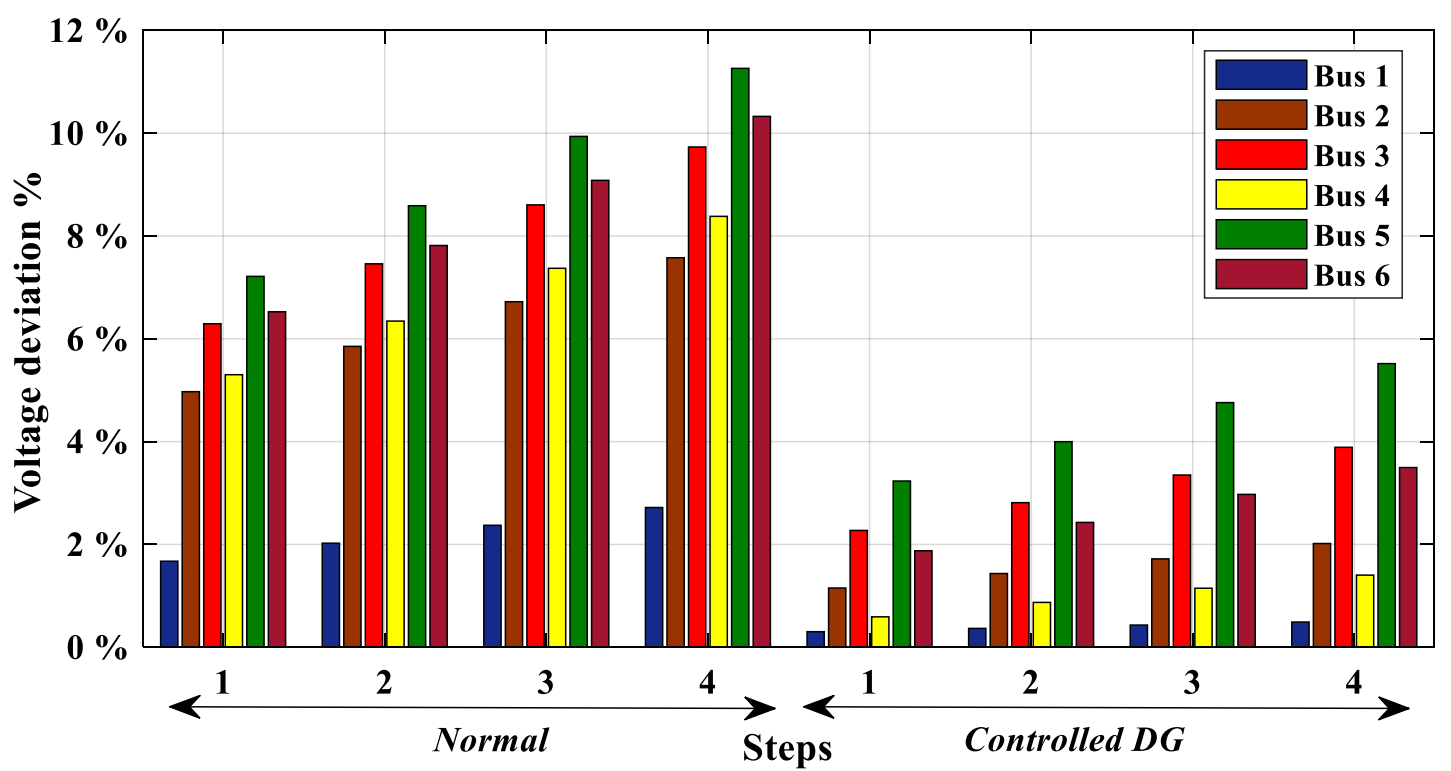

(g)

Figure 6. Voltage deviation \% for busbars: (a) Voltage deviation \% for busbar No. 1; (b) Voltage deviation \% for busbar No. 2; (c) Voltage deviation \% for busbar No. 3; (d) Voltage deviation \% for busbar No. 4; (e) Voltage deviation \% for busbar No. 5; (f) Voltage deviation \% for busbar No. 6; (g) Voltage deviation \% for all busbars.

\subsection{Sending Voltage Deviation \% of Transmission Lines}

Figure 7 and Table A5 show the percentage values of the sending voltage deviation for all transmission lines in both cases (Normal and Controlled DG) and for four steps of load values. It is obvious that the lowest percentage values of voltage deviations are for lines $0-1$ and $0-2$ as they are the closest lines to busbar 0 which is the slack bus. Further, voltage deviations for lines 1-2 and 1-4 are relatively low because they are located between two DG units. We can also notice that the highest percentage values of voltage deviations are for lines $3-5,3-4,2-3$, and $4-6$ because they are the farthest lines from the slack bus and main generators G1 and G2. In addition to that, lines 3-5 and 4-6 are radial branches. In fact, the most important thing in these results is that the impact of the DG unit's controller is still clear as it was able to decrease the percentage values of voltage deviations significantly, even for the farthest and radial transmission lines like 3-5, 3-4, and 4-6. For lines 3-5, the highest voltage deviation in the (Normal) case is about $10 \%$, while for the (Controlled DG) case, it decreases to less than $4 \%$. 


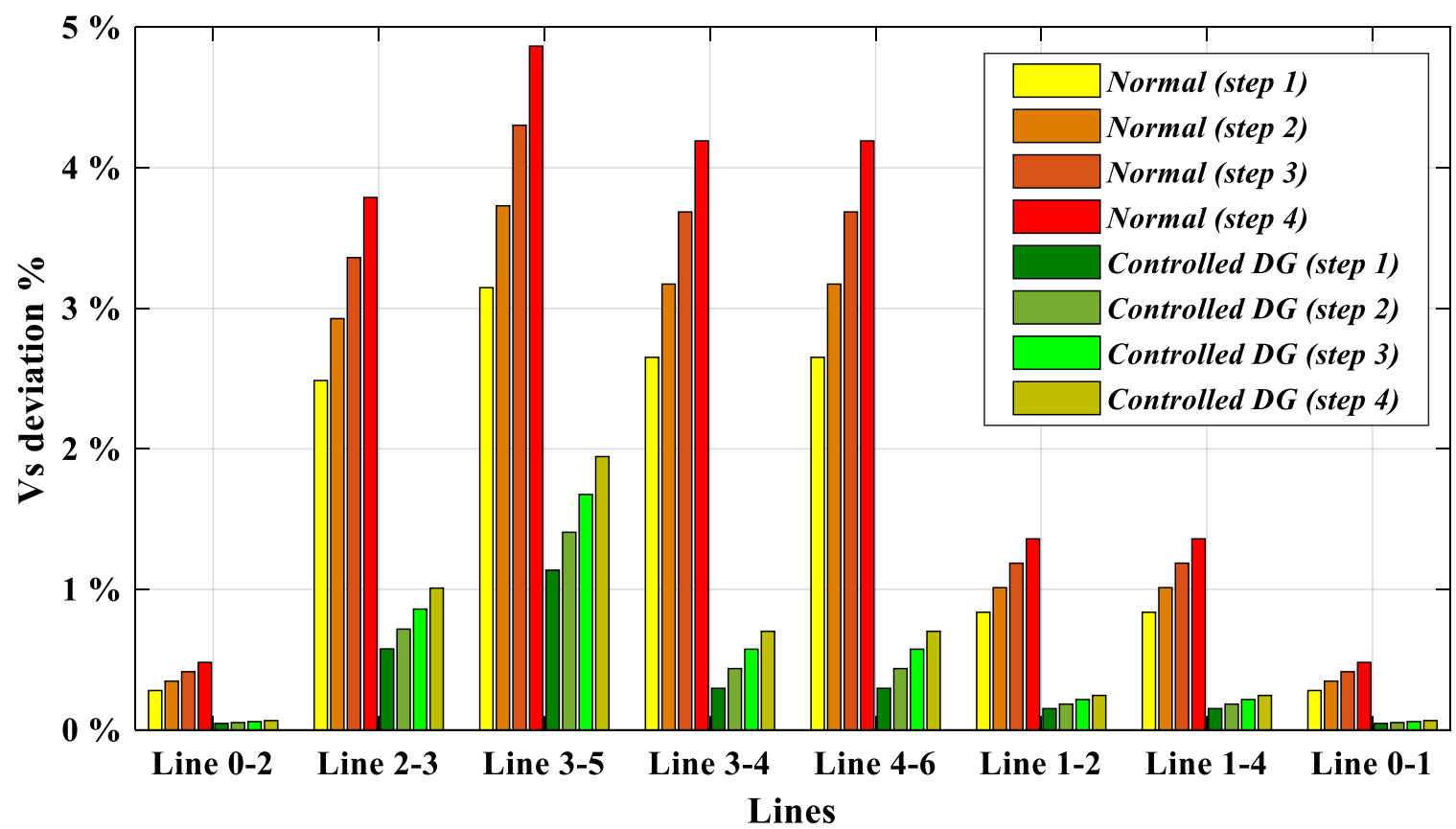

Figure 7. Sending voltage deviation $\%$ for all transmission lines.

\subsection{Receiving Voltage Deviation \% of Transmission Lines}

In Figure 8 and Table A6, we can see the percentage values of receiving voltage deviation for all transmission lines in both cases (Normal and Controlled DG) and for four steps of load values. In general, the results of sending and receiving voltage deviation are similar to each other, but with some differences in which the voltage deviations are higher for all lines because these values are for the receiving ends. The impact of the DG unit's controller is still obvious for all transmission lines even for the highest step of line $3-5$ where it was able to reduce the voltage deviation from $11.2 \%$ to about $5.5 \%$.

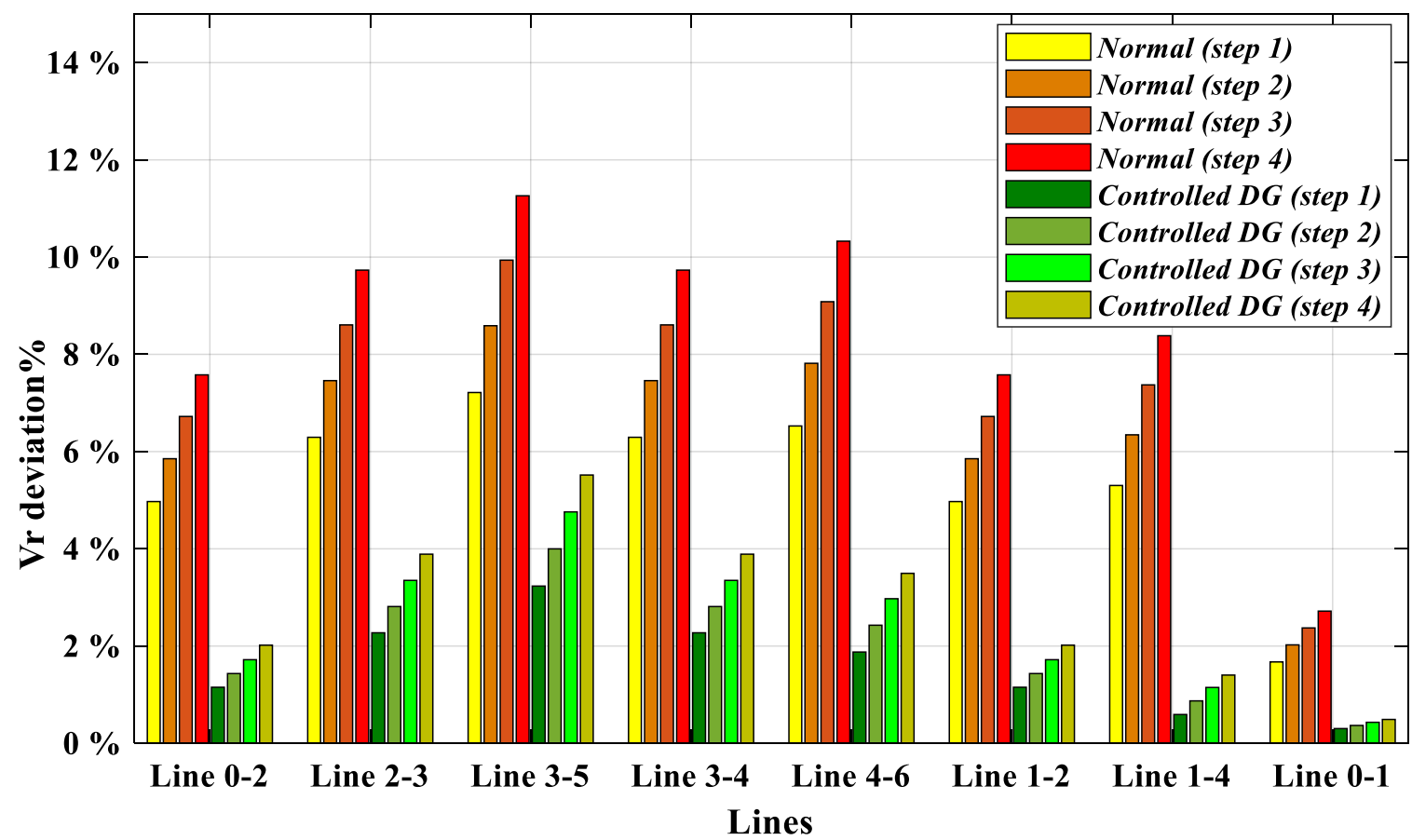

Figure 8. Receiving voltage deviation \% for all transmission lines. 


\subsection{Voltage Drop \% of Transmission Lines}

Figure 9 and Table A7 show voltage drop percentage values for all transmission lines in both cases (Normal and Controlled DG) and for four steps of load values. The most noticeable impact of the DGs unit's controller is for lines $0-1,0-2,1-2$, and 1-4, as these lines are located between two DG units or one DG unit and the slack bus. Despite this, we can notice that the voltage drop for lines 3-5 and 4-6 in the (Controlled DG) case is slightly higher than (Normal) case and relatively higher for line 3-4-but this does not mean that the (Controlled DG) case for these lines is worse than the (Normal) case because these differences between voltage drop values in the two cases are due to the differences in the improvements of sending and receiving voltage values for these lines, where the controller improves the sending voltage more than receiving voltage. For example, for line 3-4, step 4, the sending voltage was $60.467 \mathrm{kV}$ in the (Normal) case and it becomes $65.074 \mathrm{kV}$ in the (Controlled DG) case with an improving value $(4.607 \mathrm{kV})$, whereas the receiving voltage was $59.576 \mathrm{kV}$ in the (Normal) case and it became $63.432 \mathrm{kV}$, so the improving value is $3.956 \mathrm{kV}$.

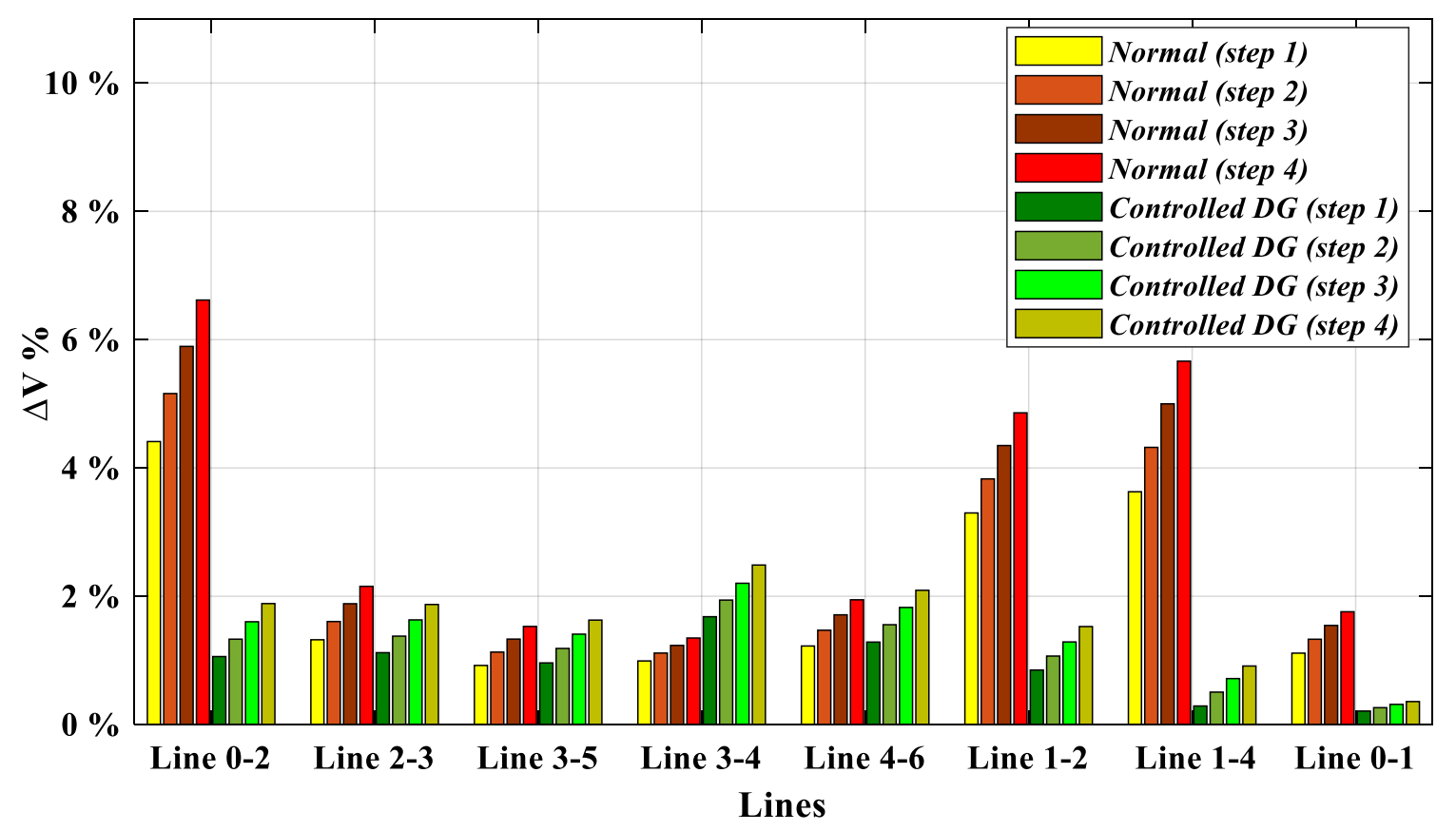

Figure 9. Voltage drop (\%) for all transmission lines.

\subsection{Sending $\cos (\varphi)$ of Transmission Lines}

In Figure 10 and Table A8, we can see the sending $\cos (\varphi)$ values for all transmission lines in both cases (Normal) and (Controlled DG) and for four steps of load values. We can notice the considerable influence of the DG unit's controller compared with the (Normal) case specifically for lines 0-2, 1-2, 1-4, and $0-1$ where the sending $\cos (\varphi)$ values are remarkably better than the (Normal) case, also very close to 1 , and the change's range during the ascending process of the load is very narrow. For example: $\cos (\varphi)$ values for line $0-2$ ranges between 0.928 and 0.952 in the (Normal) case, while in the (Controlled $D G)$ case, all the values are about 0.998 . The great improvement of $\cos (\varphi)$ values for these lines is due to the fact that all of them are located between two DG units, or between a DG unit and the slack bus. For the rest of the lines, we can notice that the sending $\cos (\varphi)$ values are relatively close to each other. 


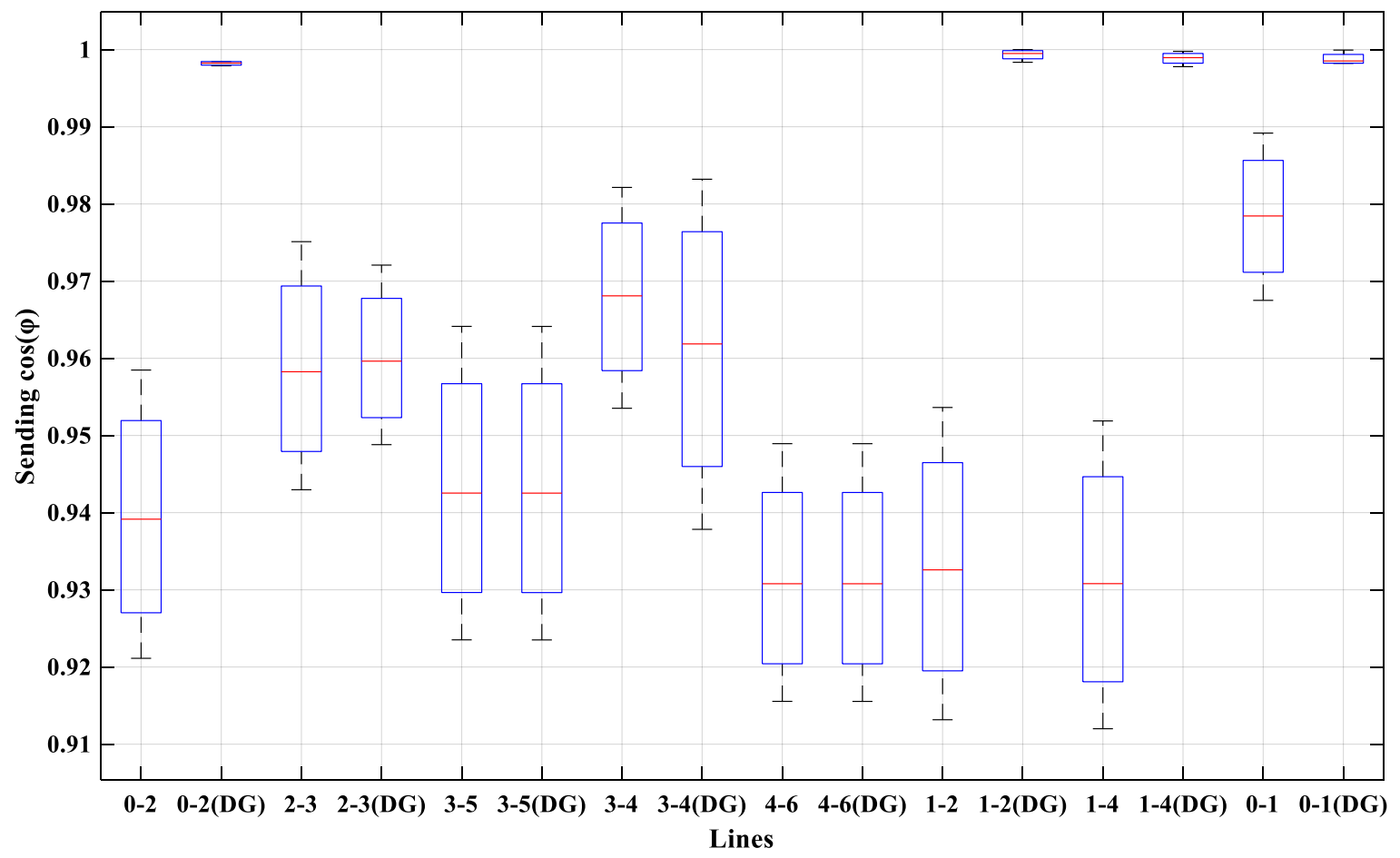

Figure 10. Sending $\cos (\varphi)$ for all transmission lines.

\subsection{Receiving $\cos (\varphi)$ of Transmission Lines}

Figure 11 and Table A9 show the receiving $\cos (\varphi)$ values for all transmission lines in both cases (Normal and Controlled DG) and for four steps of load values. The results for the receiving end are similar to the sending end where we can observe the same improvements of receiving $\cos (\varphi)$ for the same lines $0-2,1-2,1-4$, and $0-1$ but the range is relatively wider and the values are relatively lower than sending end results. For the remaining lines, the results are also close to each other for both cases, except line 3-4 where the receiving $\cos (\varphi)$ values for the Controlled $D G$ case are better than the Normal case.

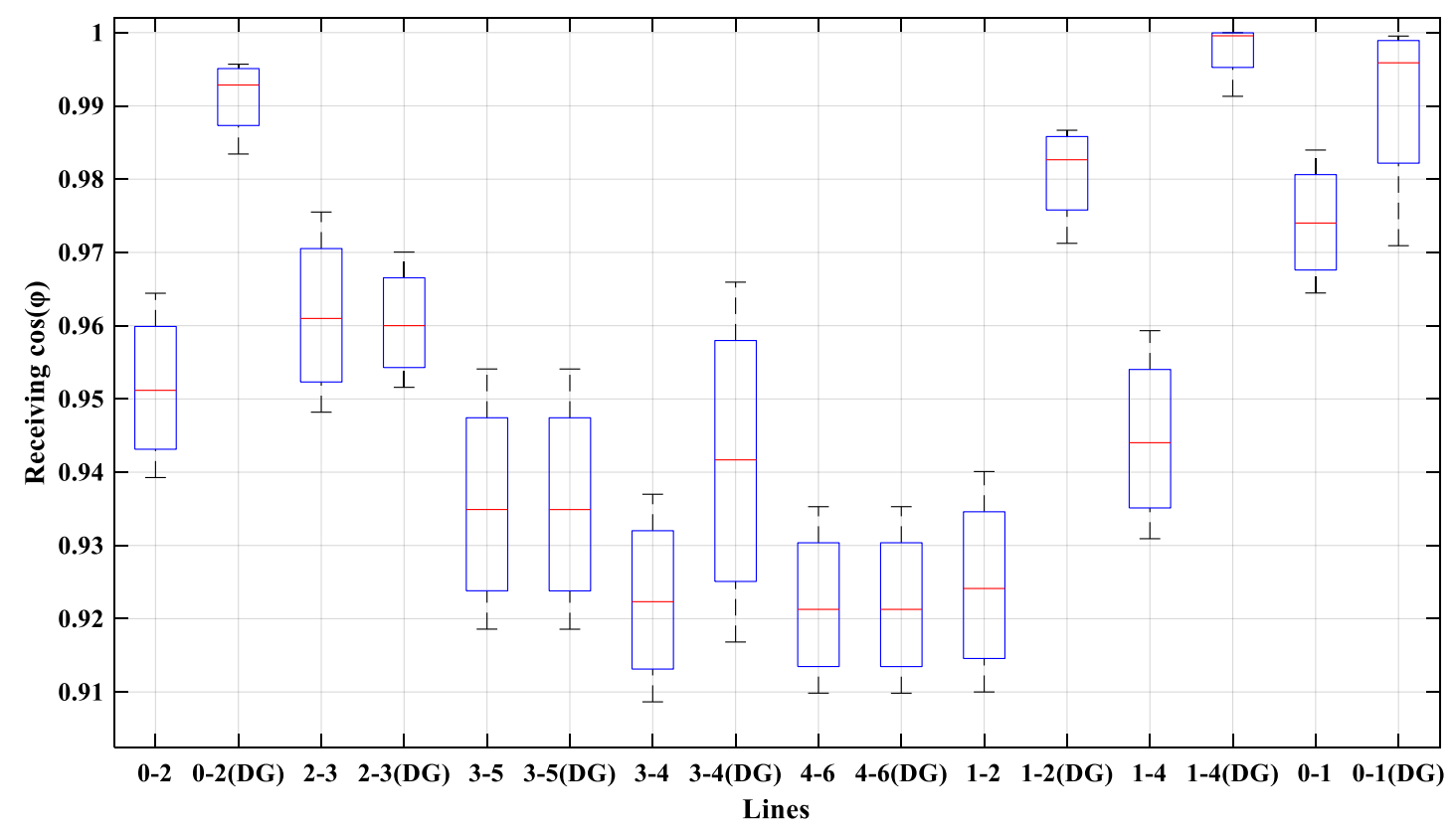

Figure 11. Receiving $\cos (\varphi)$ for all transmission lines. 


\section{Conclusions}

The results obtained from this research show that the proposed control method is efficient at improving the voltage quality and power factor for mesh grids where we had significant improvements in the voltage variation for busbars, the variation of sending and receiving voltage, voltage drop, sending and receiving $\cos (\varphi)$. Using this method, we reduced voltage drops and, therefore, the power losses and the costs have been reduced too. Moreover, the power flow through the lines has been reduced, which allows us to add new loads or to extend the distribution system. Also, we can conclude that it is important to use the admittance values between DG units and loads in order to coordinate the share of DG units in reactive power generation to maximize the benefits for all busbars and lines. Moreover, it is noticeable that the controller was efficient even for the busbars which are connected to the radial transmission lines. Despite the fact that the improvements made in the voltage quality and power factor were more noticeable for the busbars and lines connected to the DG units, we had significant positive impacts on the remaining busbars and lines. The enormous advantage of this controller is that it uses admittance and voltage variation values as inputs, which make it very efficient when we have load changes, faults, or any other unexpected case. Therefore, we obtain a better voltage quality and power factor in every case. Further, we can conclude the importance of DG units in improving the reliability of the electrical grid and improving the power quality of it. This research can be used to design the control system of DG units, especially when we have many DG units in a small area. It could also be used as the core of a technique which is suitable to be used by distributed systems operators of radial, loop, and mesh grids.

Author Contributions: All the authors contributed equally to the other parts of the work.

Funding: This research was funded by Grant Agency of the Czech Technical University in Prague (grant No. SGS17/181/OHK3/3T/13).

Acknowledgments: The financial support of the Grant Agency of the Czech Technical University in Prague (grant No. SGS17/181/OHK3/3T/13) is highly acknowledged).

Conflicts of Interest: The authors declare no conflict of interest.

\section{Appendix A}

Table A1. Parameters of the three-phase $0.575 / 66 \mathrm{kV}$ transformer of Wind farm A.

\begin{tabular}{ccc}
\hline Transformer & Low Voltage Winding & High Voltage Winding \\
\hline Connection type & Yg & Yg \\
\hline$V_{\text {rms }}(\mathrm{kV})$ & 0.575 & 66 \\
$\mathrm{R}(\Omega)$ & $1.749 \times 10^{-5}$ & 0.23048 \\
$L(\mathrm{H})$ & $1.6705 \times 10^{-6}$ & 0.022009 \\
Frequency $f_{n}(\mathrm{~Hz})$ & 50 \\
Nominal Power $S_{n}(\mathrm{MVA})$ & \multicolumn{3}{|}{15.75} \\
Magnetization resistance $R_{m}(\Omega)$ & \multicolumn{2}{c}{$1.3829 \times 10^{5}$} \\
Magnetization inductance $L_{m}(\mathrm{H})$ & $\mathrm{Inf}$ \\
\hline
\end{tabular}

Table A2. Parameters of the three-phase $0.575 / 66 \mathrm{kV}$ transformer of Wind farm B.

\begin{tabular}{ccc}
\hline Transformer & Low Voltage Winding & High Voltage Winding \\
\hline Connection type & Yg & Yg \\
\hline$V_{r m s}(\mathrm{kV})$ & 0.575 & 66 \\
$\mathrm{R}(\Omega)$ & $1.0496 \times 10^{-5}$ & 0.13829 \\
$L(\mathrm{H})$ & $1.0023 \times 10^{-6}$ & 0.013205 \\
Frequency $f_{n}(\mathrm{~Hz})$ & 50 & \\
Nominal Power $S_{n}(\mathrm{MVA})$ & & 26.25 \\
Magnetization resistance $R_{m}(\Omega)$ & \multicolumn{2}{c}{ Inf } \\
Magnetization inductance $L_{m}(\mathrm{H})$ & \multicolumn{2}{c}{} \\
\hline
\end{tabular}


Table A3. Parameters of the three-phase $0.575 / 66 \mathrm{kV}$ transformer of Wind farm A.

\begin{tabular}{ccc}
\hline Transformer & Low Voltage Winding & High Voltage Winding \\
\hline Connection type & Yg & Yg \\
\hline$V_{r m s}(\mathrm{kV})$ & 0.575 & 66 \\
$\mathrm{R}(\Omega)$ & $7.4972 \times 10^{-6}$ & 0.098776 \\
$L(\mathrm{H})$ & $7.1593 \times 10^{-7}$ & 0.0094324 \\
Frequency $f_{n}(\mathrm{~Hz})$ & 50 & \\
Nominal Power $S_{n}(\mathrm{MVA})$ & 36.75 \\
Magnetization resistance $R_{m}(\Omega)$ & 59,265 \\
Magnetization inductance $L_{m}(\mathrm{H})$ & $\mathrm{Inf}$ \\
\hline
\end{tabular}

Table A4. Voltage values of busbars for all steps and both cases (kV).

\begin{tabular}{ccccccccc}
\hline \multirow{2}{*}{ Bus No. } & \multicolumn{4}{c}{ Normal Case } & \multicolumn{3}{c}{ Controlled DG Case } \\
\cline { 2 - 9 } & Step 1 & Step 2 & Step 3 & Step 4 & Step 1 & Step 2 & Step 3 & Step 4 \\
\hline Bus 1 & 64.895 & 64.664 & 64.434 & 64.205 & 65.800 & 65.758 & 65.715 & 65.676 \\
Bus 2 & 62.718 & 62.136 & 61.563 & 60.998 & 65.239 & 65.053 & 64.865 & 64.668 \\
Bus 3 & 61.846 & 61.076 & 60.320 & 59.576 & 64.500 & 64.143 & 63.788 & 63.432 \\
Bus 4 & 62.500 & 61.812 & 61.134 & 60.467 & 65.609 & 65.424 & 65.242 & 65.074 \\
Bus 5 & 61.237 & 60.331 & 59.440 & 58.567 & 63.865 & 63.360 & 62.858 & 62.358 \\
Bus 6 & 61.692 & 60.841 & 60.005 & 59.183 & 64.761 & 64.397 & 64.037 & 63.692 \\
\hline
\end{tabular}

Table A5. Sending voltage values of lines for all steps and both cases $(\mathrm{kV})$.

\begin{tabular}{ccccccccc}
\hline \multirow{2}{*}{ Line No. } & \multicolumn{3}{c}{ Normal Case } & \multicolumn{4}{c}{ Controlled DG Case } \\
\cline { 2 - 9 } & Step 1 & Step 2 & Step 3 & Step 4 & Step 1 & Step 2 & Step 3 & Step 4 \\
\hline Line 0-2 & 65.630 & 65.541 & 65.453 & 65.366 & 65.939 & 65.931 & 65.923 & 65.912 \\
Line 2-3 & 62.718 & 62.136 & 61.563 & 60.998 & 65.239 & 65.053 & 64.865 & 64.668 \\
Line 3-5 & 61.846 & 61.076 & 60.320 & 59.576 & 64.500 & 64.143 & 63.788 & 63.432 \\
Line 0-1 & 65.630 & 65.541 & 65.453 & 65.366 & 65.939 & 65.931 & 65.923 & 65.912 \\
Line 1-2 & 64.895 & 64.664 & 64.434 & 64.205 & 65.800 & 65.758 & 65.715 & 65.676 \\
Line 3-4 & 62.500 & 61.812 & 61.134 & 60.467 & 65.609 & 65.424 & 65.242 & 65.074 \\
Line 1-4 & 64.895 & 64.664 & 64.434 & 64.205 & 65.800 & 65.758 & 65.715 & 65.676 \\
Line 4-6 & 62.500 & 61.812 & 61.134 & 60.467 & 65.609 & 65.424 & 65.242 & 65.074 \\
\hline
\end{tabular}

Table A6. Receiving voltage values of lines for all steps and both cases (kV).

\begin{tabular}{ccccccccc}
\hline \multirow{2}{*}{ Line No. } & \multicolumn{4}{c}{ Normal Case } & \multicolumn{4}{c}{ Controlled DG Case } \\
\cline { 2 - 8 } & Step 1 & Step 2 & Step 3 & Step 4 & Step 1 & Step 2 & Step 3 & Step 4 \\
\hline Line 0-2 & 62.718 & 62.136 & 61.563 & 60.998 & 65.239 & 65.053 & 64.865 & 64.668 \\
Line 2-3 & 61.846 & 61.076 & 60.320 & 59.576 & 64.500 & 64.143 & 63.788 & 63.432 \\
Line 3-5 & 61.237 & 60.331 & 59.440 & 58.567 & 63.865 & 63.360 & 62.858 & 62.358 \\
Line 0-1 & 64.895 & 64.664 & 64.434 & 64.205 & 65.800 & 65.758 & 65.715 & 65.676 \\
Line 1-2 & 62.718 & 62.136 & 61.563 & 60.998 & 65.239 & 65.053 & 64.865 & 64.668 \\
Line 3-4 & 61.846 & 61.076 & 60.320 & 59.576 & 64.500 & 64.143 & 63.788 & 63.432 \\
Line 1-4 & 62.500 & 61.812 & 61.134 & 60.467 & 65.609 & 65.424 & 65.242 & 65.074 \\
Line 4-6 & 61.692 & 60.841 & 60.005 & 59.183 & 64.761 & 64.397 & 64.037 & 63.692 \\
\hline
\end{tabular}


Table A7. Voltage drop values of lines for all steps and both cases (kV).

\begin{tabular}{ccccccccc}
\hline \multirow{2}{*}{ Line No. } & \multicolumn{4}{c}{ Normal Case } & \multicolumn{3}{c}{ Controlled DG Case } \\
\cline { 2 - 8 } & Step 1 & Step 2 & Step 3 & Step 4 & Step 1 & Step 2 & Step 3 & Step 4 \\
\hline Line 0-2 & 2.911 & 3.405 & 3.890 & 4.367 & 0.699 & 0.878 & 1.057 & 1.244 \\
Line 2-3 & 0.872 & 1.059 & 1.243 & 1.421 & 0.739 & 0.909 & 1.076 & 1.235 \\
Line 3-5 & 0.608 & 0.745 & 0.879 & 1.009 & 0.634 & 0.783 & 0.929 & 1.074 \\
Line 0-1 & 0.734 & 0.877 & 1.019 & 1.160 & 0.138 & 0.173 & 0.207 & 0.236 \\
Line 1-2 & 2.176 & 2.527 & 2.870 & 3.207 & 0.560 & 0.704 & 0.849 & 1.008 \\
Line 3-4 & 0.654 & 0.735 & 0.814 & 0.890 & 1.109 & 1.280 & 1.453 & 1.641 \\
Line 1-4 & 0.239 & 2.851 & 3.299 & 3.738 & 0.190 & 0.333 & 0.473 & 0.602 \\
Line 4-6 & 0.808 & 0.970 & 1.128 & 1.283 & 0.848 & 1.027 & 1.204 & 1.381 \\
\hline
\end{tabular}

Table A8. Sending $\cos (\varphi)$ values of lines for all steps and both cases.

\begin{tabular}{ccccccccc}
\hline \multirow{2}{*}{ Line No. } & \multicolumn{4}{c}{ Normal Case } & \multicolumn{4}{c}{ Controlled DG Case } \\
\cline { 2 - 9 } & Step 1 & Step 2 & Step 3 & Step 4 & Step 1 & Step 2 & Step 3 & Step 4 \\
\hline Line 0-2 & 0.9584 & 0.9453 & 0.9329 & 0.9211 & 0.9980 & 0.9984 & 0.9984 & 0.9978 \\
Line 2-3 & 0.9751 & 0.963 & 0.9528 & 0.942 & 0.9720 & 0.9634 & 0.9558 & 0.9488 \\
Line 3-5 & 0.964 & 0.9492 & 0.9357 & 0.9235 & 0.9641 & 0.9492 & 0.9357 & 0.9235 \\
Line 0-1 & 0.9891 & 0.9820 & 0.974 & 0.9675 & 0.9999 & 0.9988 & 0.9982 & 0.9982 \\
Line 1-2 & 0.9536 & 0.9393 & 0.9258 & 0.9131 & 0.9999 & 0.9997 & 0.9992 & 0.9983 \\
Line 3-4 & 0.9821 & 0.9729 & 0.9632 & 0.9535 & 0.9831 & 0.9696 & 0.9541 & 0.9378 \\
Line 1-4 & 0.9518 & 0.9374 & 0.924 & 0.9119 & 0.9977 & 0.9986 & 0.9992 & 0.9997 \\
Line 4-6 & 0.9489 & 0.9362 & 0.9252 & 0.9155 & 0.9489 & 0.9362 & 0.9252 & 0.9155 \\
\hline
\end{tabular}

Table A9. Receiving $\cos (\varphi)$ values of lines for all steps and both cases.

\begin{tabular}{ccccccccc}
\hline \multirow{2}{*}{ Line No. } & \multicolumn{3}{c}{ Normal Case } & \multicolumn{4}{c}{ Controlled DG Case } \\
\cline { 2 - 9 } & Step 1 & Step 2 & Step 3 & Step 4 & Step 1 & Step 2 & Step 3 & Step 4 \\
\hline Line 0-2 & 0.9644 & 0.9553 & 0.9469 & 0.9392 & 0.9834 & 0.9912 & 0.9944 & 0.9956 \\
Line 2-3 & 0.9755 & 0.9655 & 0.9564 & 0.9481 & 0.9700 & 0.9630 & 0.9569 & 0.9515 \\
Line 3-5 & 0.9540 & 0.9407 & 0.9290 & 0.9185 & 0.9540 & 0.9407 & 0.9290 & 0.9185 \\
Line 0-1 & 0.9839 & 0.9772 & 0.9707 & 0.9644 & 0.9709 & 0.9934 & 0.9983 & 0.9995 \\
Line 1-2 & 0.9400 & 0.9291 & 0.9191 & 0.9100 & 0.9712 & 0.9803 & 0.9849 & 0.9866 \\
Line 3-4 & 0.9369 & 0.9270 & 0.9176 & 0.9086 & 0.9659 & 0.9500 & 0.9333 & 0.9168 \\
Line 1-4 & 0.9593 & 0.9487 & 0.9393 & 0.9309 & 0.9913 & 0.9991 & 0.9999 & 0.9999 \\
Line 4-6 & 0.9352 & 0.9254 & 0.9171 & 0.9098 & 0.9352 & 0.9254 & 0.9171 & 0.9098 \\
\hline
\end{tabular}

\section{References}

1. Roadmap, E. 2050-COM. Bruss. Eur. Comm. 2011, 885, 1-20.

2. International Energy Agency. World Energy Outlook: Executive Summary; International Energy Agency: Paris, France, 2012; pp. 1-9.

3. International Energy Agency. Distributed Generation in Liberalised Electricity Markets; OECD Publishing: Paris, France, 2002.

4. Elmubarak, E.S.; Ali, A.M. Distributed generation: definitions, benefits, technologies \& challenges. Int. J. Sci. Res. (IJSR) 2016, 5. [CrossRef]

5. Mitani, T.; Aziz, M.; Oda, T.; Uetsuji, A.; Watanabe, Y.; Kashiwagi, T. Annual Assessment of Large-Scale Introduction of Renewable Energy: Modeling of Unit Commitment Schedule for Thermal Power Generators and Pumped Storages. Energies 2017, 10, 738. [CrossRef]

6. Fandi, G.; Krepl, V.; Ahmad, I.; Igbinovia, F.; Ivanova, T.; Fandie, S.; Muller, Z.; Tlusty, J. Design of an Emergency Energy System for a City Assisted by Renewable Energy, Case Study: Latakia, Syria. Energies 2018, 11, 3138. [CrossRef] 
7. Shaw-Williams, D.; Susilawati, C.; Walker, G. Value of residential investment in photovoltaics and batteries in networks: A techno-economic analysis. Energies 2018, 11, 1022. [CrossRef]

8. Bhullar, S.; Ghosh, S. Optimal Integration of Multi Distributed Generation Sources in Radial Distribution Networks Using a Hybrid Algorithm. Energies 2018, 11, 628. [CrossRef]

9. El-Khattam, W.; Salama, M.M. Distributed generation technologies, definitions and benefits. Electr. Power Syst. Res. 2004, 71, 119-128. [CrossRef]

10. European Commission. European Technology Platform Smart Grids: Vision and Strategy for Europe's Electricity Networks of the Future; European Commission: Brussels, Belgium, 2006.

11. Abrishambaf, O.; Faria, P.; Gomes, L.; Spínola, J.; Vale, Z.; Corchado, J.M. Implementation of a Real-Time Microgrid Simulation Platform Based on Centralized and Distributed Management. Energies 2017, 10, 806. [CrossRef]

12. Agarwal, V.; Tsoukalas, L.H. Smart grids: importance of power quality. In International Conference on Energy-Efficient Computing and Networking; Springer: Berlin/Heidelberg, Germany, 2010; pp. 136-143.

13. Prathibha, E.; Manjunath, A. An overview of power quality issues in smart grid. Dept. Int. J. Innov. Res. Adv. Eng. (IJIRAE) 2014, 1, 294-298.

14. Saxena, D.; Verma, K.; Singh, S. Power quality event classification: an overview and key issues. Int. J. Eng. Sci. Technol. 2010, 2, 186-199. [CrossRef]

15. Nabavi, S.M.H.; Hajforoosh, S.; Masoum, M.A. Placement and sizing of distributed generation units for congestion management and improvement of voltage profile using particle swarm optimization. In Proceedings of the IEEE PES Innovative Smart Grid Technologies, Perth, WA, Australia, 13-16 November 2011; pp. 1-6.

16. Junjie, M.A.; Yulong, W.; Yang, L. Size and location of distributed generation in distribution system based on immune algorithm. Syst. Eng. Procedia 2012, 4, 124-132. [CrossRef]

17. Görbe, P.; Magyar, A.; Hangos, K.M. THD reduction with grid synchronized inverter's power injection of renewable sources, SPEEDAM 2010. International Symposium on Power Electronics, Electrical Drives, Automation and Motion; IEEE: Piscataway, NJ, USA, 2010; pp. 1381-1386.

18. Neukirchner, L.; Görbe, P.; Magyar, A. Voltage unbalance reduction in the domestic distribution area using asymmetric inverters. J. Clean. Prod. 2017, 142, 1710-1720. [CrossRef]

19. Rostamzadeh, M.; Valipour, K.; Seyed-Shenava, S.J.; Khalilpour, M.; Razmjooy, N. Optimal location and capacity of multi-distributed generation for loss reduction and voltage profile improvement using imperialist competitive algorithm. Artif. Intell. Res. 2012, 1, 56-66. [CrossRef]

20. Arya, A.K.; Kumar, A.; Yadav, A. Optimal Placement and Sizing of Distributed Generators by Using Voltage Indexing \& Heuristic Method". Int. J. Recent Innov. Trends Comput. Commun. 2017, 5, 945-949.

21. Ahmad, I.; Fandi, G.; Müller, Z.; Tlustý, J. Improvement of voltage profile and mitigation of power losses in case of faults using DG units. In Proceedings of the 19th International Scientific Conference on Electric Power Engineering (EPE), Brno, Czech Republic, 16-18 May 2018; pp. 1-6.

22. Savaghebi, M.; Jalilian, A.; Vasquez, J.C.; Guerrero, J.M. Secondary control for voltage quality enhancement in microgrids. IEEE Trans. Smart Grid 2012, 3, 1893-1902. [CrossRef]

23. Prodanovic, M.; Green, T.C. High-quality power generation through distributed control of a power park microgrid. IEEE Trans. Ind. Electron. 2006, 53, 1471-1482. [CrossRef]

24. Calderaro, V.; Galdi, V.; Lamberti, F.; Piccolo, A. A smart strategy for voltage control ancillary service in distribution networks. IEEE Trans. Power Syst. 2015, 30, 494-502. [CrossRef]

25. Afandi, I.; Ciufo, P.; Agalgaonkar, A.; Perera, S. A comparison of voltage regulation and control methods. In Proceedings of the 2015 Australasian Universities Power Engineering Conference (AUPEC), Wollongong, NSW, Australia, 27-30 September 2015; pp. 1-6.

26. Yeh, H.G.; Gayme, D.F.; Low, S.H. Adaptive VAR control for distribution circuits with photovoltaic generators. IEEE Trans. Power Syst. 2012, 27, 1656-1663. [CrossRef]

27. Calderaro, V.; Galdi, V.; Massa, G.; Piccolo, A. Distributed generation management: An optimal sensitivity approach for decentralized power control. In Proceedings of the 3rd IEEE PES Innovative Smart Grid Technologies Europe (ISGT Europe), Berlin, Germany, 14-17 October 2012; pp. 1-8.

28. Tanaka, K.; Oshiro, M.; Toma, S.; Yona, A.; Senjyu, T.; Funabashi, T.; Kim, C.H. Decentralised control of voltage in distribution systems by distributed generators. IET Gener. Transm. Distrib. 2010, 4, 1251-1260. [CrossRef] 
29. Calderaro, V.; Conio, G.; Galdi, V.; Massa, G.; Piccolo, A. Optimal decentralized voltage control for distribution systems with inverter-based distributed generators. IEEE Trans. Power Syst. 2014, 29, 230-241. [CrossRef]

30. Fandi, G.; Ahmad, I.; Igbinovia, F.; Muller, Z.; Tlusty, J.; Krepl, V. Voltage regulation and power loss minimization in radial distribution systems via reactive power injection and distributed generation unit placement. Energies 2018, 11, 1399. [CrossRef]

31. Carriveau, R. Advances in wind power; IntechOpen Limited: London, UK, 2012.

32. Hansen, A.D.; Margaris, I.D. Type IV Wind Turbine Model; DTU Wind Energy: Roskilde, Denmark, 2014.

(C) 2019 by the authors. Licensee MDPI, Basel, Switzerland. This article is an open access article distributed under the terms and conditions of the Creative Commons Attribution (CC BY) license (http://creativecommons.org/licenses/by/4.0/). 